\title{
ALLELIC LOSS OF CHROMOSOME 1P AS A PREDICTOR OF UNFAVORABLE OUTCOME IN PATIENTS WITH NEUROBLASTOMA
}

\author{
Huib Garon, M.D., Ph.D., Peter van Sluis, Jan de Kraker, M.D., Ph.D., Jos Bökkerink, M.D., Ph.D., \\ Maarten Egeler, M.D., Ph.D., Geneviève Laureys, M.D., Ph.D., Rosalyn Slater, Ph.D., \\ Andries Westerveld, Ph.D., P.A. Voûte, M.D., Ph.D., and Rogier Versteeg, Ph.D.
}

\begin{abstract}
Background. Neuroblastoma is a childhood tumor derived from cells of the neural crest, with a widely variable outcome. Differences in the behavior and prognosis of the tumor suggest that neuroblastoma can be divided into several biologic subgroups. We evaluated the most frequent genetic abnormalities in neuroblastoma to determine their prognostic value.

Methods. We used Southern blot analysis to study the allelic loss of chromosomes $1 p, 4 p, 11 q$, and 14q, the duplication of chromosome 17q, and the amplification of the $\mathrm{N}$-myc oncogene in 89 neuroblastomas. We also determined the nuclear DNA content of the tumor cells.

Results. Allelic loss of chromosome 1p, N-myc amplification, and extra copies of chromosome $17 q$ were significantly associated with unfavorable outcomes. In a multivariate analysis, loss of chromosome $1 p$ was the most powerful prognostic factor. It provided strong prognostic information when it was included in multivariate
\end{abstract}

$\mathrm{N}^{1}$ EUROBLASTOMA is a childhood cancer that originates in cells of the neural crest. The clinical course of the disease varies widely. ${ }^{1}$ Patients with localized neuroblastoma (those in stages I and II) have a good prognosis after surgical resection, whereas the majority of patients with stage III or IV neuroblastoma have an adverse outcome despite intensive multimodal therapy. However, disseminated stage IVS neuroblastomas (those that would be classified as stage I or II but for the presence of remote disease confined to the liver, skin, bone marrow, or a combination of these, without radiographically detectable bone metastases) frequently undergo spontaneous regression. Factors such as age, tumor stage, tumor histology, and serum levels of lactate dehydrogenase (LDH) and ferritin are clinically meaningful but imperfect predictors of outcome..$^{2-6}$ Some patients in stages I, II, and IVS die from progressive disease, for example, whereas a minority of those in stages III and IV can be cured.

Several nonrandom genetic abnormalities have been identified in patients with neuroblastoma. These include allelic loss of chromosomes $1 \mathrm{p},{ }^{7-10} 4 \mathrm{p}$ (unpublished da-

From the Department of Pediatric Oncology and Hematology, Emma Kinderziekenhuis-Academic Medical Center (H.C., J.K., P.A.V.), and the Institute of Human Genetics, Academic Medical Center (H.C., P.S., R.S., A.W., R.V.), University of Amsterdam, Amsterdam; the Center of Pediatric Oncology of the Southeastern Netherlands, University of Nijmegen, Nijmegen (J.B.); and the Sophia Kinderziekenhuis, Erasmus University, Rotterdam (M.E.) - all in the Netherlands; and the Institute of Human Genetics, University Hospital of Ghent, Ghent, Belgium (G.L.). Address reprint requests to Dr. Caron at the Department of Pediatric Oncology and Hematology, EKZ/AMC, P.O. Box 22700, 1100 DE Amsterdam, the Netherlands.

Supported by grants from the Stichting Kindergeneeskundig Kankeronderzoek and the Dutch Cancer Society. models containing the prognostic factors of age and stage or serum ferritin level and stage. Among the patients with stage I, II, or IVS disease, the mean ( \pm SD) three-year event-free survival was 100 percent in those without allelic loss of chromosome $1 p$ and $34 \pm 15$ percent in those with such loss; the rates of three-year event-free survival among the patients with stage III and stage IV disease were $53 \pm 10$ percent and 0 percent, respectively.

Conclusions. The loss of chromosome $1 p$ is a strong prognostic factor in patients with neuroblastoma, independently of age and stage. It reliably identifies patients at high risk in stages I, II, and IVS, which are otherwise clinically favorable. More intensive therapy may be considered in these patients. Patients in stages III and IV with allelic loss of chromosome $1 p$ have a very poor outlook, whereas those without such loss are at moderate risk. (N Engl J Med 1996;334:225-30.)

○1996, Massachusetts Medical Society.

ta), $11 \mathrm{q},{ }^{11}$ and $14 \mathrm{q},{ }^{7,11,12}$ indicating loss of function of as yet unknown tumor-suppressor genes contained in those regions. Furthermore, there may be amplification of the $\mathrm{N}-m y c$ oncogene $\mathrm{e}^{13-15}$ and additional copies of part of the long arm of chromosome 17 (17q). ${ }^{16,17}$ It has been established that amplification of the N-myc oncogene has a strongly unfavorable prognostic value. ${ }^{14,15}$ A nearly diploid nuclear DNA content has also been shown to correlate with a poor response to chemotherapy and an unfavorable outcome, especially in patients under the age of two years at diagnosis. ${ }^{15-18}$ In some series, allelic loss of chromosome $1 \mathrm{p}^{7,9,19,20}$ has been associated with a poor outcome, but these results are based on the study of a limited number of patients. The prognostic value of the other genetic abnormalities has not yet been studied in detail. In this study we attempted to estimate the prognostic value of all well-established genetic abnormalities in patients with neuroblastoma.

\section{Methods}

\section{Patients and Collection of Samples}

We obtained samples of tumor tissue and blood from 101 patients with neuroblastoma. From 1990 through 1994, 77 samples were collected prospectively from the Emma Kinderziekenhuis-Academic Medical Center, the Center of Pediatric Oncology of the Southeastern Netherlands, and the Sophia Kinderziekenhuis (all in the Netherlands) and the University Hospital of Ghent (in Belgium). The study methods were approved by the institutional review board. The tumor samples were snap-frozen in the operating room and stored at $-80^{\circ} \mathrm{C}$. A further 24 tumor and control samples from the years 1984 through 1990 were obtained retrospectively from the tissue bank of the Emma Kinderziekenhuis-Academic Medical Center. The samples from eight patients were excluded, because less than 60 percent of the tumor cells they contained were histologically recognizable. The status of chromosome $1 \mathrm{p}$ could not be assessed in four patients. 


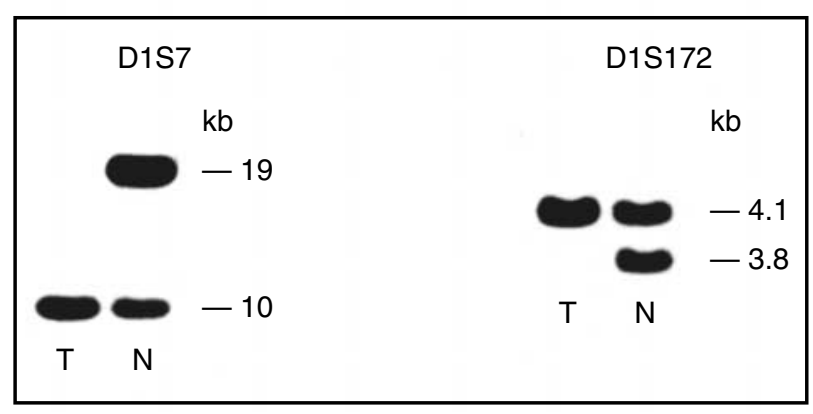

Figure 1. Autoradiographs Showing Allelic Loss of Chromosome $1 p$ in a Neuroblastoma Specimen.

The distribution of alleles at two loci in tumor tissue $(T)$ and normal tissue $(\mathrm{N})$ is shown as detected by a Taql probe.

tients tested (41 percent) had elevated serum ferritin levels, and 11 of 87 patients tested (13 percent) had serum LDH levels over $1500 \mathrm{U}$ per liter.

\section{Genetic Analysis}

We used Southern blot analysis to study allelic loss or gain in several chromosomal regions (i.e., $1 \mathrm{p}, 4 \mathrm{p}$, $11 \mathrm{q}, 14 \mathrm{q}$, and 17q) and determine the presence or absence of N-myc amplification. The principal findings and their associations with the allelic loss of chromosome $1 p$ are shown in Table 2. Allelic loss of chromosome $1 \mathrm{p}$ was found in 29 of the 89 patients (33 percent; an example of such loss is shown in Fig. 1). Allelic loss of chromosome lp was independent of the patient's age or tumor stage but correlated significantly with increased serum levels of ferritin or LDH (Table 1). $\mathrm{N}-m y c$ amplification was demonstrated in 17 of the 89 tumor samples (19 percent) (Table 2). All the patients with N-myc amplification also had allelic loss of chromosome 1p. Thirty-one of 74 patients for whom there were data (42 percent) were found to have one or more additional copies of chromosome 17q. These chromosomal gains occurred significantly more often in the patients with allelic loss of chromosome $1 \mathrm{p}$. There were allelic losses of chromosome $4 p$ in 18 of 78 patients for whom data were available (23 percent), of chromosome 1lq in 12 of 58 patients (21 percent), and of chromosome 14q in 15 of 71 patients (21 percent). None of these changes were significantly associated with allelic loss of chromosome $1 p$ or any other genetic variables studied. Furthermore, allelic loss of chromosome $4 \mathrm{p}, 11 \mathrm{q}$, or $14 \mathrm{q}$ and duplication of chromosome $17 q$ were not significantly correlated with age, tumor stage, or serum level of ferritin or LDH. A nuclear DNA content in the normal range (i.e., indicating a nearly diploid tumor) was found in 55 percent of the tumors studied, and a higher (i.e., aneuploid) DNA content in 45 percent. Significantly more of the patients with nearly diploid tumors had N-myc amplification, allelic loss of chromosome $1 \mathrm{p}$, and extra copies of chromosome 17q. Nearly diploid DNA content was also found significantly more often in stage III and IV tumors.

\section{Relation of Clinical and Genetic Factors to Outcome}

We analyzed the ability of the various clinical and genetic factors to predict clinical outcome. The analyses of event-free survival and overall survival yielded similar results, reflecting the very small possibility of a favorable outcome in patients with recurrent neuroblastoma. We therefore report the results of the analysis of event-free survival, because that end point reflects tumor behavior more directly than does overall survival. The mean period of follow-up for the entire group of patients was 40 months.

We calculated univariate hazard ratios with the proportional-hazards model (Table 3). In this analysis, all four clinical variables studied had significant prognostic value. Among the genetic variables, allelic loss of chromosome $4 \mathrm{p}, 11 \mathrm{q}$, or 14q had no prognostic value. Allelic loss of chromosome $1 \mathrm{p}$ and N-myc amplification were each associated with a high likelihood of an unfavorable outcome. In addition, extra copies of chromosome $17 \mathrm{q}$ and, to a lesser extent, nearly diploid nuclear DNA content were each associated with a bad prognosis.

\section{Multivariate Analysis}

Several genetic and clinical factors with significant prognostic value were interrelated in their ability to predict clinical outcome (Tables 1 and 2). To identify the most powerful prognostic factors, we performed multivariate analyses with the Cox proportional-hazards model. The hazard ratios calculated with two models using clinical variables are shown in Table 4. The first model contained age and tumor stage, the prognostic factors in widest use. The second model contained tumor stage and serum ferritin level, because that combination gave the best fit attainable with any

Table 3. Hazard Ratios Associated with Individual Genetic and Clinical Prognostic Factors in 89 Patients with Neuroblastoma.

\begin{tabular}{|c|c|c|c|}
\hline VARIABLE & CAtegories Compared* & $\begin{array}{c}\text { HAZARD RATIO } \\
\text { (95\% CONFIDENCE } \\
\text { INTERVAL) }\end{array}$ & P VALUE $\dagger$ \\
\hline \multicolumn{4}{|l|}{ Clinical factors } \\
\hline Stage & III or IV vs. I, II, or IVS & $5.6(2.3-13.4)$ & $<0.001$ \\
\hline Age & $\geqslant 1$ vs. $<1 \mathrm{yr}$ & $3.7(1.7-8.0)$ & 0.001 \\
\hline Ferritin & $>142$ vs. $\leqslant 142 \mu \mathrm{g} /$ liter & $6.4(3.0-13.7)$ & $<0.001$ \\
\hline $\mathrm{LDH}$ & $>1500$ vs. $\leqslant 1500$ U/liter & $4.6(2.1-9.9)$ & $<0.001$ \\
\hline \multicolumn{4}{|l|}{ Genetic factors } \\
\hline $\mathrm{N}-m y c$ & $>1$ copy vs. 1 copy & $6.8(3.5-13.4)$ & $<0.001$ \\
\hline Chromosome 1p & Loss vs. no loss & $6.7(3.4-13.3)$ & $<0.001$ \\
\hline Chromosome $4 \mathrm{p}$ & Loss vs. no loss & $0.8(0.3-2.0)$ & 0.39 \\
\hline Chromosome $11 \mathrm{q}$ & Loss vs. no loss & $1.2(0.5-2.7)$ & 0.98 \\
\hline Chromosome $14 \mathrm{q}$ & Loss vs. no loss & $1.1(0.5-2.4)$ & 0.75 \\
\hline Chromosome $17 \mathrm{q}$ & Gain vs. no gain & $3.4(1.7-6.8)$ & $<0.001$ \\
\hline Ploidy & Nearly diploid vs. aneuploid & $2.2(1.1-4.6)$ & 0.031 \\
\hline
\end{tabular}

*For each variable, the prognostic significance of the first category listed was assessed by comparing that category with the reference category (the second category listed).

$\dagger$ For the comparison of the hazard ratio shown with a hazard ratio of 1.0 (as postulated by the null hypothesis). 
Table 4. Hazard Ratios Associated with Clinical and Genetic Prognostic Factors in a Multivariate Analysis of 89 Patients with Neuroblastoma, Using Cox Proportional-Hazards Models.

\begin{tabular}{|c|c|c|c|}
\hline VARIABLE AND Model & CATEgORIES COMPARED* & $\begin{array}{c}\text { HAZARD RATIO } \\
\text { (95\% CONFIDENCE } \\
\text { INTERVAL) }\end{array}$ & P VALUE $\dagger$ \\
\hline \multicolumn{4}{|l|}{ Clinical factors } \\
\hline \multicolumn{4}{|l|}{ First model } \\
\hline Stage & III or IV vs. I, II, or IVS & $4.0(1.6-10.3)$ & 0.003 \\
\hline Age & $\geqslant 1$ vs. $<1 \mathrm{yr}$ & $2.2(0.9-5.0)$ & 0.07 \\
\hline \multicolumn{4}{|l|}{ Second model } \\
\hline Stage & III or IV vs. I, II, or IVS & $2.6(1.0-6.5)$ & 0.043 \\
\hline Ferritin & $>142$ vs. $\leqslant 142 \mu \mathrm{g} /$ liter & $4.9(2.2-11.0)$ & $<0.001$ \\
\hline \multicolumn{4}{|l|}{ Genetic factors added } \\
\hline \multicolumn{4}{|l|}{ Second model } \\
\hline Stage & III or IV vs. I, II, or IVS & $2.6(1.0-6.9)$ & 0.062 \\
\hline Ferritin & $>142$ vs. $\leqslant 142 \mu \mathrm{g} /$ liter & $2.9(1.2-6.7)$ & 0.015 \\
\hline $\mathrm{N}-m y c$ & $>1$ copy vs. 1 copy & $1.0(0.4-2.8)$ & 0.94 \\
\hline Chromosome lp & Loss vs. no loss & $4.4(1.6-11.8)$ & 0.004 \\
\hline
\end{tabular}

*For each variable, the prognostic significance of the first category listed was assessed by comparing that category with the reference category (the second category listed).

$\dagger$ For the comparison of the hazard ratio shown with a hazard ratio of 1.0 (as postulated by the null hypothesis).

combination of the four clinical prognostic factors. Adding age or serum LDH level to the second model yielded no additional prognostic information, an indication that serum ferritin levels correlate with age but provide more prognostic information.

To test whether including any of the genetic factors would add prognostic information, we included each one in both models (data not shown). N-myc status and chromosome 1p status each contributed significant prognostic information to both models. When we added the presence of extra copies of chromosome $17 \mathrm{q}$ to both models, we obtained some additional prognostic information, but this effect disappeared when either allelic loss of chromosome 1p or N-myc amplification was subsequently added to the model. Nearly diploid nuclear DNA content provided no significant prognostic information when that factor was added to either model, indicating that the prognostic value it demonstrated on univariate analysis was redundant with the prognostic value of the clinical factors.

\section{Superior Prognostic Value of Allelic Loss of Chromosome 1p}

We performed further multivariate analyses to explore the prognostic value of the allelic loss of chromosome $1 \mathrm{p}$ relative to that of $\mathrm{N}-m y c$ amplification. The simultaneous addition of chromosome $1 \mathrm{p}$ status and $\mathrm{N}-m y c$ status to the second Cox model showed that $1 \mathrm{p}$ status had the strongest predictive power when tested together with the other three factors (Table 4). When combined with loss of chromosome 1p, N-myc amplification lost its prognostic power. This indicates that allelic loss of chromosome $1 \mathrm{p}$ is superior to N-myc amplification as a prognostic factor. Allelic loss of chromosome 1p was found in all patients with N-myc amplification, and thus it identified the same patients at high risk as that factor. However, allelic loss of chromosome lp was also found in patients with a single copy of N-myc (i.e., without amplification), and it predicted their unfavorable outcome. For these patients the univariate hazard ratio associated with allelic loss of chromosome $1 \mathrm{p}$ was 3.9 (95 percent confidence interval, 1.6 to $9.6 ; \mathrm{P}=0.003)$, and they had a threeyear rate of event-free survival of $35 \pm 15$ percent. Among patients with both allelic loss of chromosome lp and N-myc amplification, the corresponding rate was 0 percent.

\section{Prognostic Value of Allelic Loss of Chromosome 1p Regardless of Age or Tumor Stage}

To gain more insight into the effect of allelic loss of chromosome $1 \mathrm{p}$ on clinical outcome we analyzed eventfree survival according to chromosome 1p status among patients of differing stages and ages. The predicted rate of event-free survival for three years among patients in stages I, II, and IVS was $83 \pm 6$ percent, as compared with $30 \pm 7$ percent among patients in stages III and IV $(\mathrm{P}=0.002)$ (Fig. 2A). Among patients with allelic loss of chromosome $1 \mathrm{p}$, the rate of event-free survival for three years was $12 \pm 7$ percent, as compared with $75 \pm 6$ percent among those in whom no such loss was detectable $(\mathrm{P}<0.001)$ (Fig. 2B). Among patients with stage I, II, or IVS disease, loss of chromosome 1p identified those in whom standard treatment was most likely to fail (three-year event-free survival, $34 \pm 15$ percent) (Fig. 2C). The remaining patients in these disease stages, who did not have allelic loss of chromosome 1p, all survived for three years without events $(\mathrm{P}<0.001)$. Among patients with stage III or IV disease, loss of chromosome 1p defined a very-high-risk group, none of whose members survived for three years free of events, whereas among those who did not have such loss the three-year eventfree survival was $53 \pm 10$ percent $(\mathrm{P}<0.001)$ (Fig. 2D).

Among the 52 patients one year old or older, none of the 17 who had $1 \mathrm{p}$ loss in their tumors survived without events for three years, whereas the rate of three-year event-free survival was $52 \pm 9$ percent in the 35 who did not have $1 \mathrm{p}$ loss $(\mathrm{P}<0.001)$. Among the 37 patients less than one year old, the three-year event-free survival in the 12 with allelic loss of 1 p was $32 \pm 15$ percent, as compared with 100 percent in the 25 without such loss $(\mathrm{P}<0.001)$.

The group of patients with N-myc amplification was a subgroup of the patients with $1 \mathrm{p}$ loss. Therefore, the patients without N-myc amplification constituted a group in which loss of chromosome $1 \mathrm{p}$ had additional prognostic value. The clinical characteristics of these two groups with allelic loss of chromosome lp differed. N-myc amplification occurred together with lp loss mainly in patients with stage III or IV disease (16 of 17 patients) and in patients one year old or older (13 of 17 patients). Among the 72 patients without N-myc amplification, 12 (17 percent) had allelic loss of chromosome 1p. Three of these 12 patients had stage IV tumors and 
A

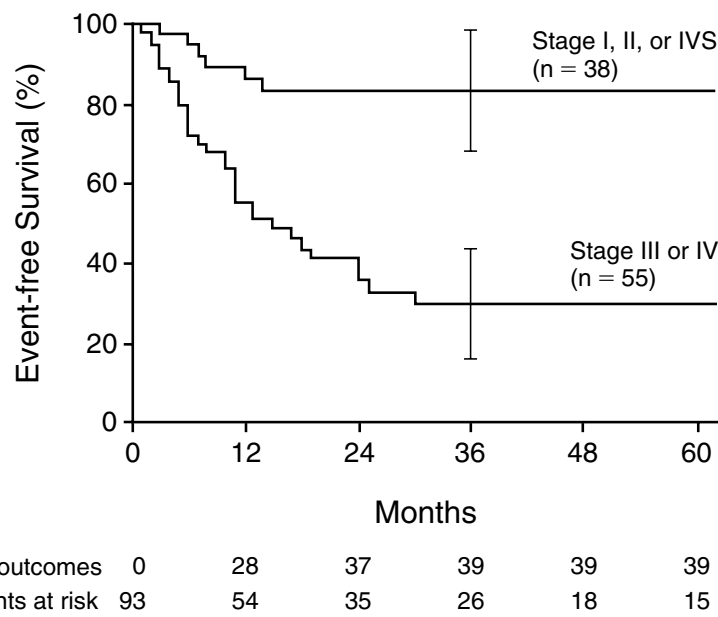

C

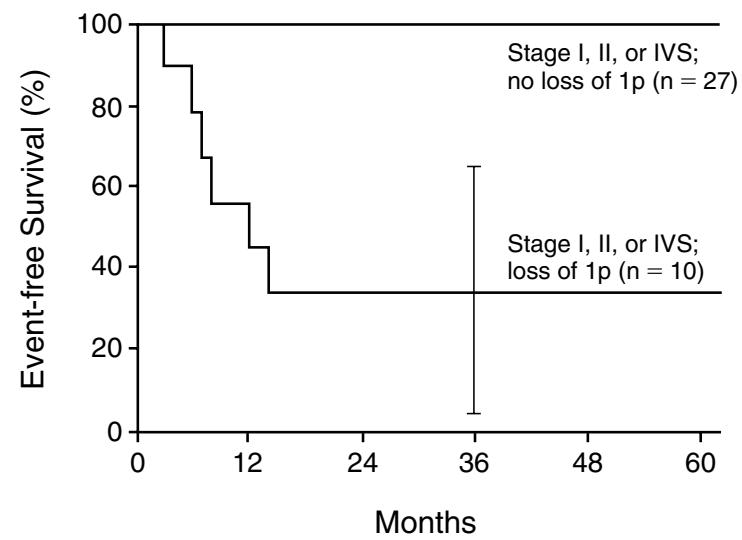

$\begin{array}{lllllll}\text { Poor outcomes } & 0 & 28 & 37 & 39 & 39 & 39\end{array}$
B

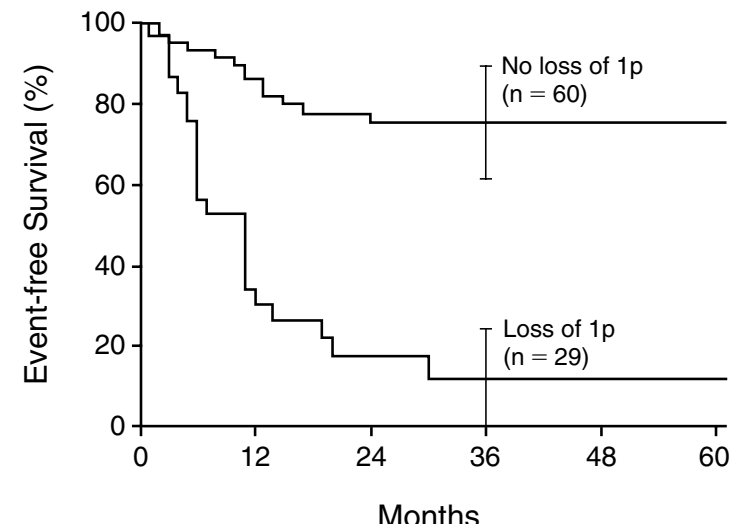

$\begin{array}{lrlllll}\text { Poor outcomes } & 0 & 27 & 34 & 36 & 36 & 36 \\ \text { Patients } & 27 & 35 & 25 & 17\end{array}$

D

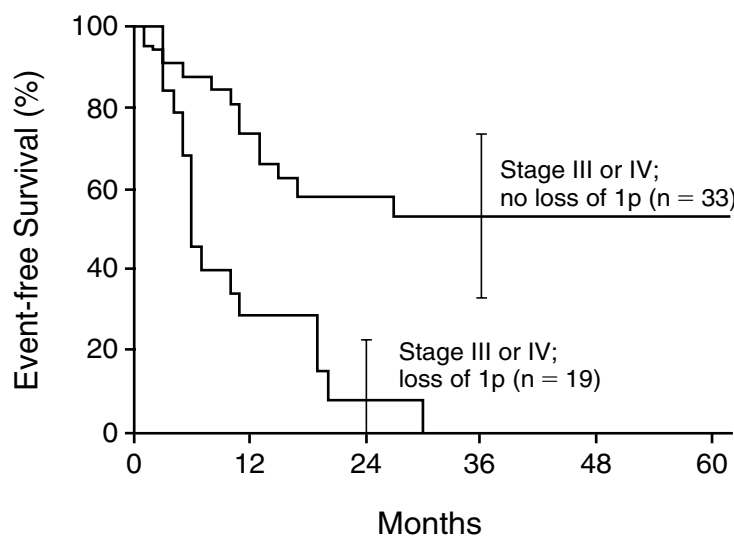

Poor outcomes 0

5

$6 \quad 6$

$6 \quad 6$

Poor outcomes 0

22

29

30

30

Patients at risk $52 \quad 24$

12

Figure 2. Kaplan-Meier Curves for Event-free Survival.

The study population of patients with neuroblastoma is analyzed according to stage in Panel $\mathrm{A}$ and according to chromosome $1 \mathrm{p}$ status in Panel B. Patients with stage I, II, or IVS disease are analyzed according to chromosome 1p status in Panel C, and patients with stage III or IV disease are analyzed according to chromosome 1p status in Panel D. Vertical bars show the 95 percent confidence intervals for three-year event-free survival, except for the group in Panel D with stage III or IV disease and allelic loss of chromosome $1 \mathrm{p}$, for whom the bar shows two-year survival without events.

were one year old or older. The remaining nine patients, who had lp loss but no N-myc amplification, had stage I, II, or IVS neuroblastomas, and eight of these patients were less than one year old. This shows that among the patients without N-myc amplification, most of those at high risk who were identified on the basis of allelic loss of chromosome lp were under the age of one year and had stage I, II, or IVS tumors.

\section{Discussion}

Our study found that allelic loss of chromosome $1 \mathrm{p}$ is a powerful prognostic indicator in patients with neuroblastoma. Univariate testing showed that four genetic variables (allelic loss of chromosome 1p, N-myc amplification, extra copies of chromosome $17 \mathrm{q}$, and a nearly diploid nuclear DNA content) were significant predictors of unfavorable outcome. The prognostic val- ue of N-myc amplification in neuroblastoma is well established. ${ }^{14,15}$ In this study, allelic loss of chromosome $1 p$ was found to be a better prognostic indicator than N-myc amplification. The latter was present in a subgroup of patients whose tumors had allelic loss of chromosome 1p. Moreover, patients whose neuroblastomas had a single copy of N-myc and allelic loss of chromosome 1p were at high risk for an unfavorable outcome. The presence of extra copies of chromosome $17 \mathrm{q}$ and nearly diploid nuclear DNA content were of only minor prognostic significance as compared with allelic loss of chromosome $1 \mathrm{p}$ and N-myc amplification.

The main clinical value of allelic loss of chromosome $1 \mathrm{p}$ as a prognostic factor lies in its ability to detect patients at high risk among those who do not have N-myc amplification. For patients with stage I, II, or IVS disease, N-myc amplification was a rare event and was not 
present in the majority of patients with an unfavorable outcome. Patients with stage I, II, or IVS disease who had $1 p$ loss (12 percent of the patients in this series) were at a higher risk for recurrence than those who did not have such loss (three-year event-free survival, 34 percent vs. 100 percent). In patients such as the former, more aggressive therapy at diagnosis may be considered. Patients with stage I, II, or IVS disease without allelic loss of chromosome lp (30 percent of the patients in this series) had an excellent prognosis (three-year event-free survival, 100 percent). In this group of patients, therapy should be as minimal as possible and should be viewed in the light of possible late effects. Among patients in stages III and IV, additional patients at very high risk who did not have N-myc amplification were identified on the basis of $1 \mathrm{p}$ loss. However, in this group the additional prognostic value of $1 p$ loss was limited, because most of the patients at very high risk had N-myc amplification together with allelic loss of chromosome 1p. The current intensive multimodal therapy may be especially useful for patients with stage III or IV disease but no $1 \mathrm{p}$ loss, whereas more innovative therapeutic approaches may be justified in patients with stage III and IV disease who have such loss.

The association between allelic loss of $1 \mathrm{p}$ and outcome has been described in three other studies. Fong et al. ${ }^{7}$ described five patients without $\mathrm{N}-m y c$ amplification who had allelic loss of chromosome $1 \mathrm{p}$, three of whom remained disease-free for more than three years. Ambros et al. ${ }^{20}$ studied 42 stage I and II neuroblastomas with single copies of $\mathrm{N}-m y c$. Among the 5 patients with $1 \mathrm{p}$ loss, 3 had recurrences, as compared with 1 of the remaining 37 patients without such loss. Takeda et al. ${ }^{9}$ described four patients with allelic loss of $1 \mathrm{p}$ and no $\mathrm{N}-m y c$ amplification who had a relatively short mean follow-up of 15 months and did not have events. In our series, the 12 patients with allelic loss of chromosome $1 \mathrm{p}$ and a single copy of the $\mathrm{N}-m y c$ gene had a relative risk of recurrent disease of 3.9 , with a three-year eventfree survival of 35 percent. Taken together, these data indicate that allelic loss of chromosome $1 \mathrm{p}$ identifies more patients who are likely to have an unfavorable outcome than does N-myc amplification alone. However, some patients whose tumors have allelic loss of chromosome $1 \mathrm{p}$ and a single copy of the N-myc gene are long-term survivors. Thus, the principal advantage of using allelic loss of chromosome $1 \mathrm{p}$ as a prognostic factor is in identifying high-risk patients among those with single copies of N-myc, the majority of whom have stage I, II, or IVS neuroblastomas.

We are indebted to J. Groot-Loonen, K. Hählen, H. Hey, R. Lippens, K. Moorman-Voestermans, Y. Meijer, N. Schouten-van Meeteren, and M. van Weel for providing blood and tumor samples; to J.H. Bras for assistance with the histologic analyses; to A.J.M. de Craen for assistance with the statistical analysis; and to J. Armour, A. Frischauf, M. Schwab, G. Vergnaud, the Japanese Cancer Resources Bank, and the American Type Culture Collection for making DNA probes available to us.

\section{REFERENCES}

1. Voûte PA, de Kraker J, Hoefnagel CA. Tumors of the sympathetic nervous system: neuroblastoma, ganglioneuroma and phaeochromocytoma. In: Voûte PA, Barrett A, Lemerle J, eds. Cancer in children: clinical management. 3rd ed. Berlin, Germany: Springer-Verlag, 1992.

2. Berthold F, Trechow R, Utsch S, Zieschang J. Prognostic factors in metastatic neuroblastoma: a multivariate analysis of 182 cases. Am J Pediatr Hematol Oncol 1992;14:207-15.

3. Shuster JJ, McWilliams NB, Castleberry R, et al. Serum lactate dehydrogenase in childhood neuroblastoma: a Pediatric Oncology Group recursive partitioning study. Am J Clin Oncol 1992;15:295-303.

4. Silber JH, Evans AE, Fridman M. Models to predict outcome from childhood neuroblastoma: the role of serum ferritin and tumor histology. Cancer Res 1991;51:1426-33.

5. Shimada H, Chatten J, Newton WA Jr. Histopathologic prognostic factors in neuroblastic tumors: definition of subtypes of ganglioneuroblastoma and an age-linked classification of neuroblastomas. J Natl Cancer Inst 1984; 73:40516.

6. Joshi VV, Cantor AB, Altshuler G, et al. Age-linked prognostic categorization based on a new histologic grading system of neuroblastomas: a clinicopathologic study of 211 cases from the Pediatric Oncology Group. Cancer 1992;69:2197-211.

7. Fong CT, White PS, Peterson K, et al. Loss of heterozygosity for chromosomes 1 or 14 defines subsets of advanced neuroblastomas. Cancer Res 1992;52:1780-5.

8. Caron HN, van Sluis P, van Hoeve M, et al. Allelic loss of chromosome $1 \mathrm{p} 36$ in neuroblastoma is of preferential maternal origin and correlates with N-myc amplification. Nat Genet 1993;4:187-90. [Erratum, Nat Genet 1993; 4:431.]

9. Takeda O, Homma C, Maseki N, et al. There may be two tumor suppressor genes on chromosome arm 1p closely associated with biologically distinct subtypes of neuroblastoma. Genes Chromosom Cancer 1994;10:30-9.

10. Schleiermacher G, Peter M, Michon J, et al. Two distinct deleted regions on the short arm of chromosome 1 in neuroblastoma. Genes Chromosom Cancer 1994;10:275-81.

11. Srivatsan ES, Murali V, Seeger RC. Loss of heterozygosity for alleles on chromosomes 11q and 14q in neuroblastoma. Prog Clin Biol Res 1991;366: 91-8.

12. Suzuki T, Yokota J, Mugishima H, et al. Frequent loss of heterozygosity on chromosome 14q in neuroblastoma. Cancer Res 1989;49:1095-8.

13. Schwab M, Alitalo K, Klempnauer KH, et al. Amplified DNA with limited homology to myc cellular oncogene is shared by human neuroblastoma cell lines and a neuroblastoma tumor. Nature 1983;305:245-8.

14. Seeger RC, Brodeur GM, Sather H, et al. Association of multiple copies of the N-myc oncogene with rapid progression of neuroblastoma. N Engl J Med 1985;313:1111-6.

15. Bourhis J, De Vathaire F, Wilson GD, et al. Combined analysis of DNA ploidy index and N-myc genomic content in neuroblastoma. Cancer Res 1991;51:33-6.

16. Van Roy N, Laureys G, Cheng NC, et al. 1;17 Translocations and other chromosome 17 rearrangements in human primary neuroblastoma tumors and cell lines. Genes Chromosom Cancer 1994;10:103-14.

17. Caron HN, van Sluis P, van Roy N, et al. Recurrent 1;17 translocations in human neuroblastomas reveal nonhomologous mitotic recombination during the S/G2 phase as a novel mechanism for loss of heterozygosity. Am J Hum Genet 1994;55:341-7.

18. Look AT, Hayes FA, Nitschke R, McWilliams NB, Green AA. Cellular DNA content as a predictor of response to chemotherapy in infants with unresectable neuroblastoma. N Engl J Med 1984;311:231-5.

19. Caron HN. Allelic loss of chromosome 1 and additional chromosome 17 material are both unfavourable prognostic markers in neuroblastoma. Med Pediatr Oncol 1995;24:215-21.

20. Ambros PF, Ambros IM, Strehl S, et al. Regression and progression in neuroblastoma: does genetics predict tumor behaviour? Eur J Cancer 1995; 31A:510-6.

21. Evans AE, D'Angio GJ, Randolph J. A proposed staging system for children with neuroblastoma: children's cancer study group A. Cancer 1971;27:3748.

22. Hedley DW, Friedlander ML, Taylor IW, Rugg CA, Musgrove EA. Method for analysis of cellular DNA content of paraffin-embedded pathological material using flow cytometry. J Histochem Cytochem 1983;31:1333-5.

23. Campos-Filho N, Franco EL. Microcomputer-assisted univariate survival data analysis using Kaplan-Meier life table estimators. Comput Methods Programs Biomed 1988;27:223-8.

24. Idem. A microcomputer program for multiple logistic regression by unconditional and conditional maximum likelihood methods. Am J Epidemiol 1989;129:439-44. 